\title{
Declared value for the thermal conductivity coefficient of insulation corkboard
}

\author{
L. Matias, C. Santos, M. Reis, L. Gil
}

Summary This study presents the results of a set of tests for the determination of the thermal conductivity coefficient of samples extracted from boards of Insulation Corkboard (ICB) withdrawn from the usual production of the seven portuguese factories.

These tests were carried out as a part of an interlaboratorial study integrated in the standardization program for cork of the sub-comission 4 of The National Technical Committee of Standardization (CT 16), in which participated the Cork Technological Centre (CTCOR), the National Laboratory of Civil Enginneering (LNEC) and the National Institute of Engineering and Industrial Technology (INETI). The purpose of this study aimed to contribute to the definition of the "declared value" of this thermal property to be included in the future European Standard (EN) specifying the characteristics of ICB for thermal insulating of buildings which is in preparation in the $88^{\mathrm{Th}}$ Technical Committee of The European Committee of Standardization CEN/TC-88 (CEN 1995).

In view of the results, the declared value of thermal conductivity proposed was $0.045 \mathrm{~W} / \mathrm{m} .{ }^{\circ} \mathrm{C}$.

\section{Introduction}

Insulation corkboard (ICB), also called pure corkboard, is exclusively made of cork. This product is manufactured mainly with granules from cork strippings (virgin cork) obtained from pruned branches of the cork oak tree (Quercus Suber L.).

After grinding and partial cleaning of the cork strips, the granules, usually in the range of 5-20 mm, are placed into an autoclave, undergo light compression (precompression), and after steaming at $300-350^{\circ} \mathrm{C}$ and $30-60 \mathrm{kPa}$, the particles are self-bonded (and expanded) without the use of external adhesives. This

\section{Received 9 February 1996}

L. Matias, C. Santos

National Laboratory of Civil Engineering

Av. do Brasil, 101, P-1799 Lisboa Codex, Portugal

M. Reis

Cork Technological Centre - South Unit

Apartado 101, P-2870 Montijo, Portugal

L. Gil

National Institute of Engineering and Industrial Technology

Estrada das Palmeiras, P-2745 Barcarena, Portugal 
process usually originates agglomerates in block form, which upon cooling are cut into boards.

Although such agglomerate is produced with the lowest quality types of cork, it has very good properties for some applications, e.g. acoustical, thermal and vibratory insulation, shock and sound absorber, and is a completely natural product (Gil 1994).

The European Committee for Standardization has several Technical Committees in various areas. One of these Committees, the CEN/TC-88 designated "Thermal insulating materials and products" includes working group 13 "Thermal insulating products for buildings - Factory made products of cork (ICB)" (CEN 1995).

Besides the test methods, the specifications of the products are also being prepared, where amongst the most important are the thermal properties of this material, namely the declared value for the thermal conductivity $\left(\lambda_{\text {decl }}\right)$.

To know this value in a representative way, a global interlaboratorial study was performed (three Laboratories) including samples obtained from all seven Portuguese factories producing this material. The three participating Laboratories were the Cork Technological Centre (CTCOR), the National Laboratory Civil of Engineering (LNEC) and the National Institute of Engineering and Industrial Technology (INETI) designated in this work by Lab 1, Lab 2 and Lab 3.

In this study several samples were tested, using two types of equipment, different material thicknesses and different operational conditions, being the declared value calculated as a function of individual values and the number of measurements through an established criteria.

\section{Experimental procedure}

Usually the determination of the thermal conductivity is made according to the guarded hot plate (absolute method) and the heat flow meter (relative method) methods. In both cases the determination is achieved after obtaining conditions of permanent regime (Matias et al. 1994). The tests carried out by the three Labs were made according to the heat flow meter method using two types of equipment which differ in the maximum dimensions allowed for the samples. In two Labs (Lab 1 e Lab 2) the equipment used allows the test of samples with maximum dimensions of $300 \mathrm{~mm} \times 300 \mathrm{~mm} \times 100 \mathrm{~mm}$, while in the third Lab the samples may have maximum dimensions of $200 \mathrm{~mm} \times 200 \mathrm{~mm} \times 50 \mathrm{~mm}$. Both equipments allow testing according to the general requirements defined in the International Standard ISO 8301 "Thermal insulation. Determination of steady-state thermal resistance and related properties. Heat flow meter apparatus" (ISO 1991) which will be adopted in the future European Standardization of thermal insulating materials.

In this study samples of ICB boards with nominal thicknesses of $30 \mathrm{~mm}$ and $50 \mathrm{~mm}$ were tested. Each factory provided a set of twelve boards of both nominal thicknesses, being all specimens tested in at least one Lab.

The determination of the thermal conductivity was made after samples, conditioning at a temperature of $23 \pm 2{ }^{\circ} \mathrm{C}$ and $50 \pm 5 \%$ relative humidity (standard environment $23 / 50$ ), and afterwards, after the corresponding drying in a ventilated kiln $\left(103 \pm 2{ }^{\circ} \mathrm{C}\right)$ for a minor set of specimens.

The thermal conductivity tests were made at mean temperatures of $10^{\circ} \mathrm{C}$ and $23^{\circ} \mathrm{C}$. Two Labs performed the tests at one mean test temperature only (Lab 2 at $10^{\circ} \mathrm{C}$ and $\mathrm{Lab} 3$ at $23^{\circ} \mathrm{C}$ ) while the third one determined the thermal conductivity of some specimens at mean temperatures of $10^{\circ} \mathrm{C}$ and $23^{\circ} \mathrm{C}$, being the rest of the 
tests made at the mean temperature of $10^{\circ} \mathrm{C}$. The temperature gradient applied through the test specimen was of, approximately, $20^{\circ} \mathrm{C}$.

The thermal conductivity values obtained in the tests carried out, at the mean temperature of $10^{\circ} \mathrm{C}$ and $23{ }^{\circ} \mathrm{C}$, were designated by $\lambda_{10}(23 / 50), \lambda_{10}(\mathrm{dry})$ and $\lambda_{23}(23 / 50), \lambda_{23}(\mathrm{dry})$, according to the previous conditioning of the samples.

\section{Results and discussions}

The three Labs performed a total of 378 tests of thermal conductivity determinations of which two thirds were performed after conditioning in a standard environment $23 / 50$ and one third after drying the specimens in a ventilated kiln $\left(103 \pm 2^{\circ} \mathrm{C}\right)$. Representative graphics of the distribution of the thermal conductivity values of the samples coming from each factory determined by each Lab were based on these results. For example, Figs. 1 and 2 show the ranges of values obtained by Lab 2 for the samples tested at mean temperature of $10^{\circ} \mathrm{C}$, after previous conditioning in a standard environment $23 / 50$ and after drying the samples.

The analysis of the results of the three Labs consisted in a general analysis of the thermal conductivity values obtained at the test mean temperatures of $10^{\circ} \mathrm{C}$ and $23^{\circ} \mathrm{C}$, followed by the study of the influence of two factors - the nominal thickness and the density - which, due to the characteristics of the tested product
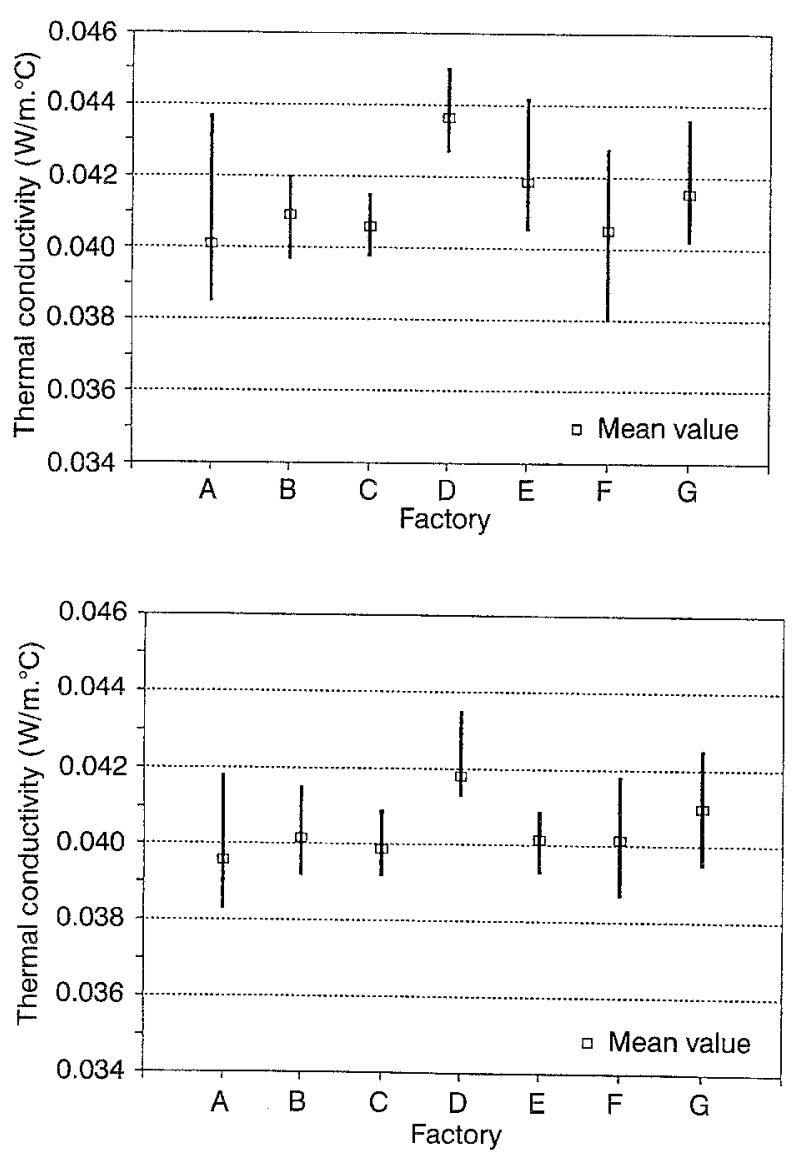

Fig. 1. Ranges of thermal conductivity values of ICB samples submitted at a $23 / 50$ conditioning. Tests made by Lab 2 at mean temperature of $10{ }^{\circ} \mathrm{C}$
Fig. 2. Ranges of thermal conductivity values of ICB samples after drying in a ventilated kiln $\left(103 \pm 2{ }^{\circ} \mathrm{C}\right)$. Tests made by Lab 2 at mean temperature of $10^{\circ} \mathrm{C}$ 
may, eventually, become important for the values of the corresponding thermal conductivity.

\section{Global analysis}

In this global analysis the whole set of results obtained was considered, for the mean test temperatures of $10^{\circ} \mathrm{C}$ and $23^{\circ} \mathrm{C}$, independently of the nominal thickness of the samples and of the factory which produced those boards.

For each Lab and mean test temperature it was obtained: the distributions of thermal conductivity values of the samples submitted at the two standard environment; the relation between the dry thermal conductivity values $(\lambda($ dry $))$ and after conditioning $23 / 50(\lambda(23 / 50))$; and the relation between $\lambda(23 / 50)$ and $\lambda($ dry $)$ as a function of the moisture content determined after conditioning at 23/50. Examples of these representations can be observed in the Figs. 3, 4 and 5 .

For the mean test temperature of $10^{\circ} \mathrm{C}$ there are results, coming from two Labs, which refer to the same samples. Thus, in the Figs. 6 and 7 it can be seen the relations between the values of the thermal conductivities after conditioning 23/50, and corresponding final moistures contents, obtained by Lab 1 and Lab 2 .
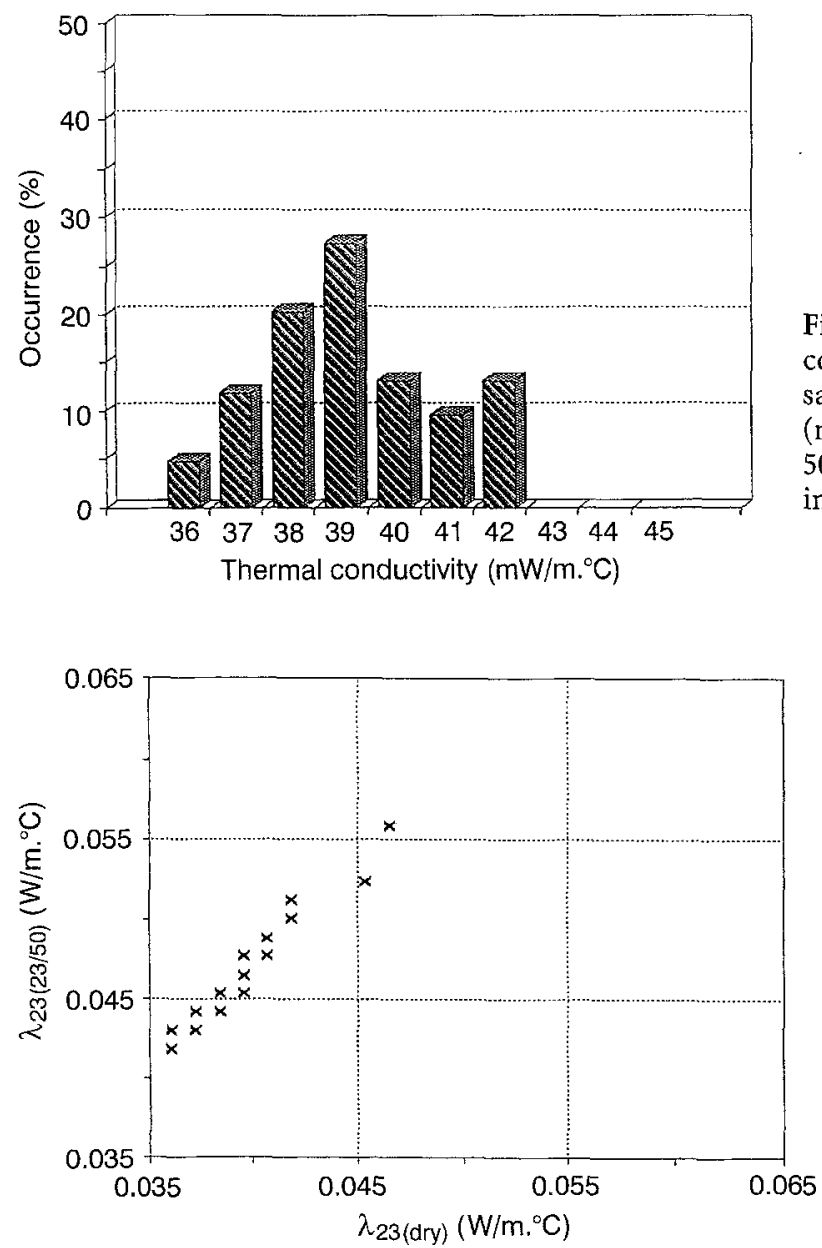

Fig. 3. Histogram of thermal conductivity values of ICB samples tested by Lab 1 (nominal thicknesses of 30 and $50 \mathrm{~mm}$ ). Previous conditioning in a $23 / 50$ environment
Fig, 4. Relation between the values $\lambda_{23}(23 / 50)$ and $\lambda_{23}$ (dry) obtained in tests of determination of thermal conductivity of ICB samples with nominal thickness of 30 $\mathrm{mm}$. Tests made by Lab 3 

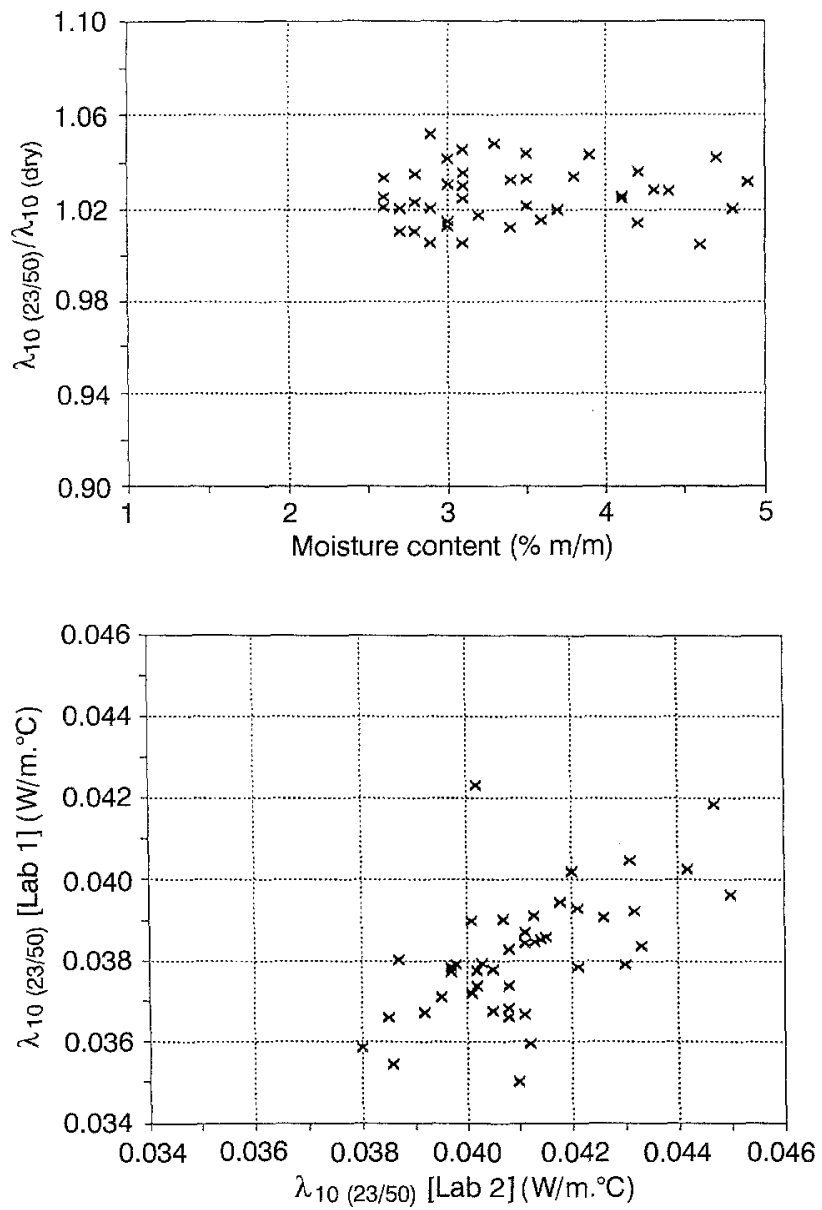

Fig. 5. Relation $\lambda_{10}(23 / 50) / \lambda_{10}(\mathrm{dry})$, as a function of the moisture determined at the end of the test for ICB samples with nominal thicknesses of $30 \mathrm{~mm}$ and $50 \mathrm{~mm}$. Tests made by Lab 2

Fig. 6. Relation between the values $\lambda_{10}(23 / 50)$ obtained by Lab 1 and Lab 2

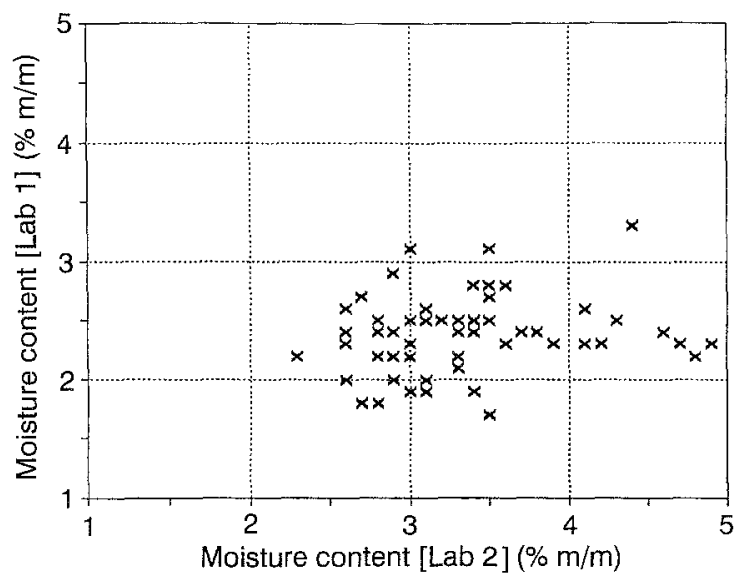

Fig. 7. Relation between the moisture obtained by Lab 1 and $\mathrm{Lab} 2$ at the end of the tests of ICB samples submitted at conditioning 23/50

Figure 6 shows that the thermal conductivity values obtained with the same samples by Lab 1, are inferior to those obtained by Lab 2. This difference is probably due to the fact that there are sensible differences between the moisture content of the samples after conditioning in the two Labs (Fig. 7). 

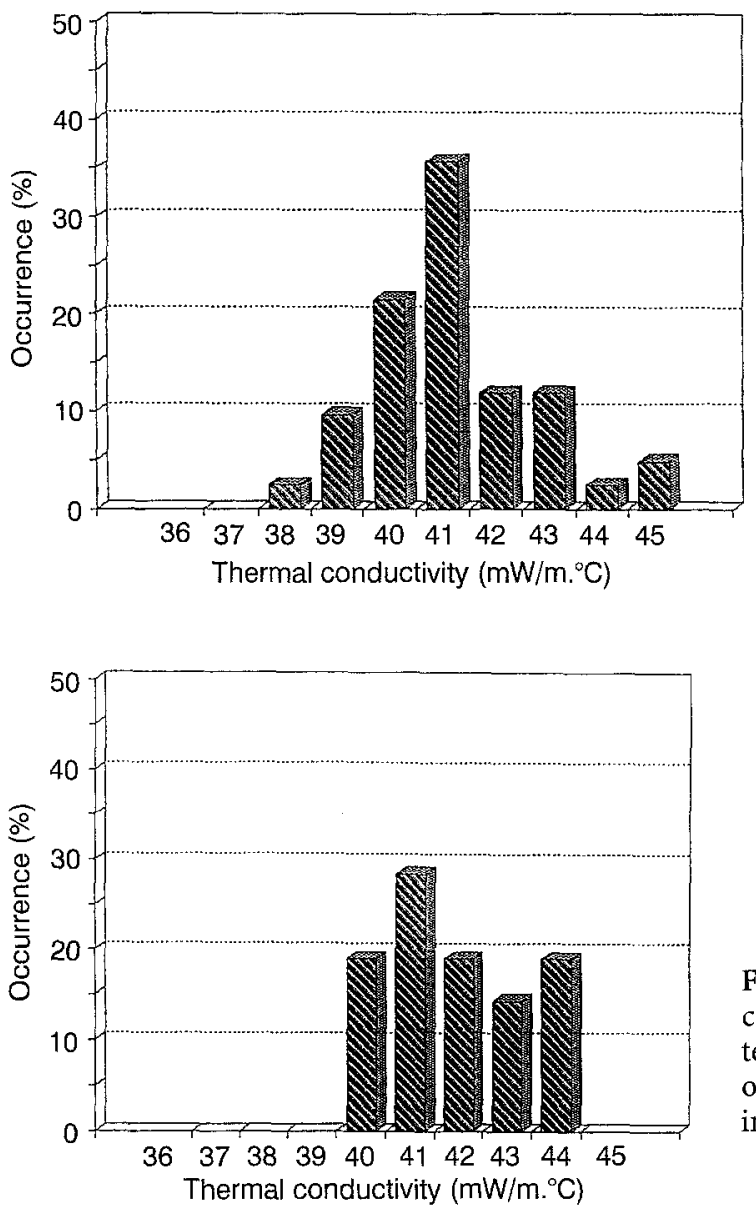

Fig. 8. Histogram of thermal conductivity values of ICB samples tested by Lab 2 (nominal thickness of $30 \mathrm{~mm}$ ). Previous conditioning in a 23 / 50 environment
Fig. 9. Histogram of thermal conductivity values of ICB samples tested by Lab 2 (nominal thickness of $50 \mathrm{~mm}$ ). Previous conditioning in a $23 / 50$ environment

\section{Influence of the sample thickness}

Trying to find an influence of the nominal thickness of the samples in the results, the thermal conductivity values obtained were analysed, for each thickness and each conditioning, at mean test temperatures of $10^{\circ} \mathrm{C}$ and $23^{\circ} \mathrm{C}$.

The analysis of the graphics obtained with the values determined by the three Labs showed that the distribution of thermal conductivity values is more regular in the samples having a nominal thickness of $50 \mathrm{~mm}$. Besides that, in terms of ranges of values it can be concluded that the ranges corresponding to the samples of $50 \mathrm{~mm}$ are a little bit narrower than those corresponding to the samples of $30 \mathrm{~mm}$.

Figures 8 and 9 represent the thermal conductivity values distributions obtained by Lab 2 at mean test temperature of $10^{\circ} \mathrm{C}$, after conditioning at $23 / 50$, for samples of nominal thicknesses, respectively of 30 and $50 \mathrm{~mm}$.

\section{Influence of density}

After the recognized heterogeneity and variability of the quality of the raw material used in the manufacture production of ICB boards, the density could be a parameter with sensitive influence in the corresponding values of the thermal conductivity. 

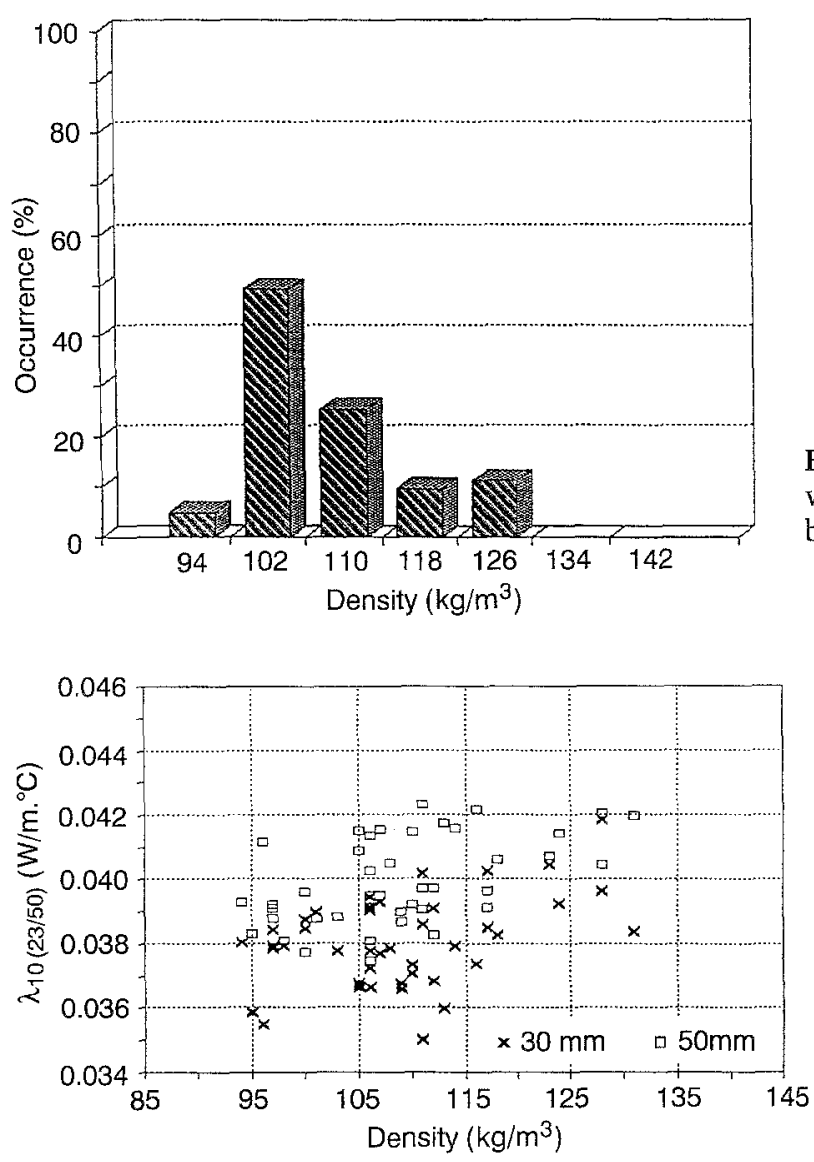

361

Fig. 10. Histogram of density values of ICB specimens tested by Lab 2
Fig. 11. Thermal conductivity values of ICB samples with nominal thicknesses of $30 \mathrm{~mm}$ and $50 \mathrm{~mm}$. Relation between $\hat{\lambda}_{10}(23 / 50)$ and density values

Figure 10 represents the histogram referring to the density of the samples tested by Lab 2.

The graphic representation of the thermal conductivity values as a function of the density showed that, in spite of being observed a certain trend in the increase of the thermal conductivity with density, the registered scattering is significant. This fact is well illustrated in Fig. 11.

\section{Declared value for the thermal conductivity}

According to the Draft of the European Specification Standard for ICB boards for thermal insulation of buildings (CEN 1995), the declared value of the thermal conductivity $\left(\lambda_{\text {decl }}\right)$ must represent at least $90 \%$ of the population with a confidence level of $90 \%$ (Matias et al. 1994).

In statistical terms this value represents the upper limit of a statistical dispersion range, which defines a unilateral fraction of $90 \%$ with a confidence level of $90 \%$. This statistical limit is designated by the $90 \%$ fractile (ISO 1994).

The reference conditions specified in the Draft European Standard for the calculation of the declared value of the thermal conductivity of a production are:

- Previous conditioning of the samples in an 23/50 environment for 48 hours.

- Determination of the thermal conductivity following requirements of the International Standards ISO 8301 (ISO 1991) or ISO 8302 (ISO 1992). 
The $90 \%$ fractile may be calculated using the mean $\left(\lambda_{\mathrm{m}}\right)$ and the standard deviation $\left(s_{\lambda}\right)$ estimate of $n$ measurements of the thermal conductivity $\left(\lambda_{i}\right)$ or the standard deviation of the population $\left(\sigma_{2}\right)$ if it is known.

When the standard deviation of the population is unknown, as is the case in this study, $\lambda_{\text {decl }}$ is calculated using the equation (ISO 1994, ISO/CEN 1993):

$\lambda_{\mathrm{decl}}=\lambda_{\mathrm{m}}+\mathrm{k} \cdot \mathrm{s}_{\lambda}$

The correction factor $k$ is a coefficient for unilateral tolerance when the standard deviation of the population is unknown. This coefficient is function of the desired 362 fraction, the confidence level and the number of measurements, $n$ (ISO 1994).

This coefficient is given in Table 1 , for a fraction of $90 \%$ with a confidence level of $90 \%$, as a function of the number of measurements, $n$.

Tables 2 and 3 show the declared value of the thermal conductivity calculated from the results of the tests performed at the three Labs.

In each Lab the declared value was calculated for each factory and for each nominal thickness $(30$ and $50 \mathrm{~mm})$. In some cases the declared values were calculated from only three results, and this fact negatively affects the value obtained (three is the minimum number of data to obtain $\lambda_{\mathrm{dec}}$ ). In view of the analysis of the influence of the thickness in the thermal conductivity, the declared value was calculated for each factory for all samples tested, assuring a minimum number of 9 results for each factory.

Considering the variability of the raw-material used in the production of the ICB boards, the declared values were calculated for all the samples of each nominal thickness and for all the tested samples.

Tables 2 and 3 show the declared values achieved for the samples tested at the mean temperature of $10^{\circ} \mathrm{C}$, after a previous conditioning in a standard environment 23/50, by Lab 1 and Lab 2 .

Table 1. Correction factor $\mathrm{k}$ for estimation of the $90 \%$ fractile (ISO/CEN 1993)

\begin{tabular}{|c|c|c|c|c|c|c|c|c|c|c|}
\hline $\mathrm{n}$ & 3 & 6 & 9 & 12 & 20 & 25 & 30 & 40 & 50 & 100 \\
\hline k & 4.26 & 2.49 & 2.13 & 1.97 & 1.77 & 1.70 & 1.66 & 1.60 & 1.56 & 1.47 \\
\hline
\end{tabular}

Table 2. Declared values of thermal conductivity of ICB samples tested at mean temperature of $10^{\circ} \mathrm{C}$. Tests done by Lab 1

\begin{tabular}{|c|c|c|c|c|c|c|}
\hline \multirow[t]{3}{*}{ Factory } & \multicolumn{6}{|c|}{ Sample thickness (mm) } \\
\hline & \multicolumn{2}{|l|}{30} & \multicolumn{2}{|l|}{50} & \multicolumn{2}{|c|}{$30+50$} \\
\hline & $\mathrm{n}$ & $\begin{array}{l}\lambda_{\text {decl }} \\
\left(\mathrm{W} / \mathrm{m} .{ }^{\circ} \mathrm{C}\right)\end{array}$ & $\mathrm{n}$ & $\begin{array}{l}\lambda_{\text {decl }} \\
\left(\mathrm{W} / \mathrm{m} .{ }^{\circ} \mathrm{C}\right)\end{array}$ & $\mathrm{n}$ & $\begin{array}{l}\lambda_{\text {decl }} \\
\left(\mathrm{W} / \mathrm{m} .{ }^{\circ} \mathrm{C}\right)\end{array}$ \\
\hline A & 6 & 0.039 & 6 & 0.044 & 12 & 0.043 \\
\hline B & 6 & 0.041 & 6 & 0.041 & 12 & 0.040 \\
\hline C & 6 & 0.040 & 6 & 0.040 & 12 & 0.040 \\
\hline D & 6 & 0.043 & 6 & 0.043 & 12 & 0.043 \\
\hline E & 6 & 0.042 & 6 & 0.042 & 12 & 0.041 \\
\hline F & 6 & 0.040 & 6 & 0.040 & 12 & 0.040 \\
\hline G & 6 & 0.041 & 6 & 0.043 & 12 & 0.044 \\
\hline A to $G$ & 42 & 0.042 & 42 & 0.042 & 84 & 0.041 \\
\hline
\end{tabular}


Table 3. Declared values of thermal conductivity of ICB samples tested at mean temperature of $10^{\circ} \mathrm{C}$. Tests done by Lab 2

\begin{tabular}{|c|c|c|c|c|c|c|}
\hline \multirow[t]{3}{*}{ Factory } & \multicolumn{6}{|c|}{ Sample thickness (mm) } \\
\hline & \multicolumn{2}{|l|}{30} & \multicolumn{2}{|l|}{50} & \multicolumn{2}{|c|}{$30+50$} \\
\hline & $\mathrm{n}$ & $\begin{array}{l}\lambda_{\text {decl }} \\
\left(\mathrm{W} / \mathrm{m} .{ }^{\circ} \mathrm{C}\right)\end{array}$ & $\mathrm{n}$ & $\begin{array}{l}\lambda_{\mathrm{decl}} \\
\left(\mathrm{W} / \mathrm{m} .{ }^{\circ} \mathrm{C}\right)\end{array}$ & $\mathrm{n}$ & $\begin{array}{l}\lambda_{\text {decl }} \\
\left(\mathrm{W} / \mathrm{m} .{ }^{\circ} \mathrm{C}\right)\end{array}$ \\
\hline A & 6 & 0.041 & 3 & 0.049 & 9 & 0.043 \\
\hline B & 6 & 0.043 & 3 & 0.042 & 9 & 0.043 \\
\hline $\mathrm{C}$ & 6 & 0.042 & 3 & 0.042 & 9 & 0.042 \\
\hline D & 6 & 0.046 & 3 & 0.047 & 9 & 0.045 \\
\hline E & 6 & 0.045 & 3 & 0.047 & 9 & 0.044 \\
\hline $\mathrm{F}$ & 6 & 0.042 & 3 & 0.044 & 9 & 0.044 \\
\hline G & 6 & 0.042 & 3 & 0.046 & 9 & 0.043 \\
\hline A to $G$ & 42 & 0.044 & 21 & 0.044 & 63 & 0.044 \\
\hline
\end{tabular}

Observing the two tables we verify that the declared values achieved from the results of Lab 1 were lower than the values obtained by Lab 2. Yet, it is noted that the declared values in Lab 1 for each factory are nearly always equal whatever the nominal thicknesses ( 30 or $50 \mathrm{~mm}$ ), while in Lab 2 the declared values for samples with nominal thickness of $50 \mathrm{~mm}$ are, usually, higher than the values corresponding to $30 \mathrm{~mm}$. It must be referred, nevertheless, that Lab 2 tested only three samples with thickness of $50 \mathrm{~mm}$ for each factory, fact that can affect, significantly, the declared value, in particular if there is a great dispersion of the individual values.

The declared value of the thermal conductivity must be calculated from results of tests carried out at mean temperature of $10^{\circ} \mathrm{C}$, after a previous conditioning in a standard environment $23 / 50$. Nevertheless, the declared values for samples tested at mean temperature of $23^{\circ} \mathrm{C}$ were also calculated with the purpose to observe the variation of the declared values caused by the different mean testing temperatures.

Table 4 shows the declared values obtained for the samples at mean temperature of $23^{\circ} \mathrm{C}$ by Lab 1, after conditioning in environment 23/50.

Table 4. Declared values of thermal conductivity of ICB samples tested at mean temperature of $23^{\circ} \mathrm{C}$. Tests done by Lab 1

\begin{tabular}{lll}
\hline Factory & \multicolumn{2}{l}{ Thickness of $50 \mathrm{~mm}$} \\
\cline { 2 - 3 } & $\mathrm{n}$ & $\begin{array}{l}\lambda_{\text {decl }} \\
\left(\mathrm{W} / \mathrm{m} .{ }^{\circ} \mathrm{C}\right)\end{array}$ \\
\hline A & 3 & 0.049 \\
$\mathrm{~B}$ & 3 & 0.043 \\
$\mathrm{C}$ & 3 & 0.043 \\
$\mathrm{D}$ & 3 & 0.045 \\
E & 3 & 0.044 \\
F & 3 & 0.043 \\
G & 3 & 0.043 \\
A to G & 21 & 0.044 \\
\hline
\end{tabular}


Comparing Tables 2 and 4, since only Lab 1 performed tests at the two mean temperatures, it is noted that for the mean temperature of $23^{\circ} \mathrm{C}$ the declared values are slightly higher than the values that have been obtained with mean temperature of $10^{\circ} \mathrm{C}$. Nevertheless, we can note that only three samples were tested.

\section{Conclusions}

The high number of determinations of the thermal conductivity of ICB samples, in well defined reference conditions, allowed the identification of the influence of various factors in that parameter.

A first and very important factor which stands out from this study is the difference observed, in some cases very significative, in the results achieved by the three test Labs. Therefore it must be said that there is a need to make interlaboratorial calibration of the equipments used and the respective materials of reference (calibration patterns).

The preconditioning of samples was made in a different way by the various Labs. This fact could explain part of the differences found in the measured values of moisture content and thermal conductivity. It is quite justifiable, with the continuation of these studies, the necessity of presetting the time of preconditioning of the samples, specially in the standard environment 23/50.

Another conclusion of the present interlaboratorial study is that tests of thermal conductivity determination on dry samples are quicker (less time of equipment stabilization), the results show lower dispersion, and require less expensive equipment (ventilated kiln versus climatized chamber), a fact that can, eventually, be more suitable for factory control. For that, it is necessary to obtain corrective factors which may estimate the thermal conductivity value, after conditioning in standard environment, based on values obtained with dry samples.

Nevertheless, the results obtained in this study by the three Laboratories are not conclusive enough for, at once, propose such a corrective factor.

The global analysis of the results of all the tests carried out at the three Labs which participated in this interlaboratorial study can show that the influence of the quality of raw-material and the transformation process used by the manufacturers introduce a variability in the $\lambda_{10}$ value that dissimulates the influence of other factors, namely, the density.

In view of the results, the declared value of thermal conductivity proposed was $0.045 \mathrm{~W} / \mathrm{m} .{ }^{\circ} \mathrm{C}$, which will be included in the future European Standard (EN) for the specification of characteristics of ICB boards for thermal insulating of buildings. The difference observed in the results obtained for each factory and the reduced number of results for each of them, justifies a necessity to carry out more regular tests, in order to enable a more consistent statistical analysis.

\section{References}

Gil, L. 1994: Effects of hot pressing densification on the cellular structure of black agglomerated corkboard. Holz als Roh- und Werstoff 52: 131-134

Comité Européen de Normalisation (CEN) 1995: Thermal insulating products for building applications. Factory made products from expanded agglomerated cork. CEN/TC 88 WG13 N243

Matias, L. M.; Santos, C. P.; Reis, M. J.; Gil, L. M. 1994: Ensaios de determinação da condutibilidade térmica de placas de aglomerado negro de cortiça. In Portuguese. LNEC: Relatório conjunto 
International Organization for Standardization (ISO) 1991: Thermal insulation - Determination of steady-state thermal resistance and related properties-Heat flow meter apparatus. ISO 8301

ISO 1994: Isolation thermique. Materiaux et produits du bâtiment. Détermination des valeurs déclarées et de calcul. ISO/DIS 10456

ISO 1992: Thermal insulation - Determination of steady-state thermal resistance and related properties - Guarded hot plated apparatus. ISO 8302

ISO/CEN 1993: Statistical methods for quality control of building materials and components. ISO/CEN TC98/SC2/WG3 